\title{
5. How China can address threats to food and nutrition security from the COVID-19 outbreak
}

\author{
Kevin Chen, Yumei Zhang, Yue Zhan, Shenggen Fan, and Wei Si
}

Since the outbreak of the COVID-19 pandemic, China's national and local governments have adopted stringent mitigation policies, including mandatory lockdowns, suspension of public transportation, and travel restrictions. While these measures are necessary, they could potentially lead to hiccups in food and nutrition security. Pandemics like Ebola, Severe Acute Respiratory Syndrome (SARS), and Middle East Respiratory Syndrome (MERS) all had negative impacts on food and nutrition security - particularly for vulnerable populations including children, women, the elderly, and the poor. For example, when Ebola first hit Guinea, Liberia, and Sierra Leone in 2014, rice prices in those countries increased by more than $30 \%$; the price of cassava, a major staple in Liberia, skyrocketed by $150 \%$. In 2003, the SARS outbreak delayed China's winter wheat harvest by two weeks, triggering food market panics in Guangdong and Zhejiang, though production and prices were largely unaffected in the rest of China.

Since the beginning of the outbreak in late December, food prices have remained stable in Wuhan, in Hubei province - and in fact, all over China. Supplies of staples, fruits, vegetables, and meats have been adequate despite sporadic reports of price hikes and shortages in isolated locations. But there is no room for complacency. Media reports indicate that the poultry industry is already under stress due to a lack of adequate feed supply and interruptions in the timely marketing of its products. If nothing is done, the poultry supply could begin tightening, and these problems could spread to other industries - creating a food supply hiccup and a threat to food and nutrition security for many.

\section{The current situation}

Disruptions are not expected to be severe, as the food supply has been sufficient and the market has been basically stable, at least so far. Wuhan has been under lockdown since January 23 to contain the spread of the virus. Restrictions on transportation and movement of people have led to some food logistics challenges. However, as the lockdown began just before the Chinese New Year on January 25, most citizens had already stocked food, and businesses had established reserves of goods for the holidays, so food prices have not been significantly affected. In February, China's consumer price index, a gauge of inflation, went up 5.2\% year-on-year. But food prices surged $21.9 \%$, largely due to pork price hikes triggered by the impact of African swine fever on hog production. On a month-on-month basis, national consumer prices rose $0.8 \%$, while food prices increased $4.3 \%$, led by an uptick in the prices of fresh vegetables and meat. However, in March, both the consumer price index and food prices index declined on a month-on-month basis, falling $1.2 \%$ and $2.7 \%$, respectively. The price of fresh vegetables has returned to normal after a surge in February, indicating a modest impact of COVID-19 on China's food market. 
The poultry industry has suffered more adverse effects. Transportation blockages create difficulties for distribution of inputs like feed, and some firms have already encountered input shortages, difficulties in product delivery, and labor shortages. The ban on the movement of live poultry (believed to be a potential disease risk) has stopped farmers from getting chickens and eggs to market, and has led some to bury chicks and ducklings alive. According to industry estimates, market input of chickens and ducklings has decreased by about $50 \%$. Coupled with the extended impact of African swine fever, supplies of meat could plunge. According to data from the National Bureau of Statistics, pork production dropped by $29.1 \%$ and total meat production decreased by $19.5 \%$ in the first quarter year-on-year.

The food system beyond agriculture has also been significantly affected, and these impacts will grow if processing enterprises cannot restart production in the near future. Only $24 \%$ of agricultural products are directly consumed by households, while $77 \%$ are used as intermediate inputs, $41 \%$ go to food processing enterprises, and $3 \%$ are used by restaurants. In the wake of the coronavirus outbreak, many orders were canceled and many restaurants had to close their doors. The supply of processed foods remained relatively abundant. According to data from the National Bureau, production in food industries - such as sugar, meat, and rice processing - decreased only modestly or maintained growth in February. But production may also be affected by a lack of workers and falling demand for agricultural products. One priority, then, has been allowing migrant workers to return to these jobs.

Production of staple food crops such as wheat, rice, and vegetables is expected to remain stable. The 2014 Ebola epidemic led to an increase in abandoned agricultural areas and reduced fertilizer use in West Africa. If staple food production is affected, the impact on food security could be grave. China is seeing reassuring signs for staple foods, with spring planting going smoothly, and recorded a 3.5\% year-on-year increase in the added value of the country's planting industry and had sufficient daily food supplies.

Domestic and international trade disruptions may trigger food market panics. During the 2003 SARS outbreak, panic-buying of food and other essentials hit many places in China. If this happens again, it would exacerbate temporary food shortages, lead to price spikes, and disrupt markets. If not controlled quickly, food panics can spread and threaten broader social stability. Export restrictions and the potential imposition of nontariff trade barriers, on the premise of safety concerns, would also exert negative impact on food supply chains. The 2007-2008 food price crisis reminds us that export bans can drive food prices up and cause volatility. Unfortunately, 11 countries currently have active binding export restrictions on food.

Restrictions on mobility may lead to labor shortages. Many companies have given workers extended leave in response to the outbreak; this could leave many manufacturing and service enterprises without enough workers. Large numbers of migrant workers who returned to their hometowns for the New Year break were trapped there by quarantine measures. The number of migrant workers who returned to work declined by $30 \%$ at the end of February in 2020 compared to the same period in 2019. The resulting labor shortage will likely impact both domestic and global supply chains. 


\section{How has China responded?}

Fortunately, the government has been targeting these problems since the early stage of the outbreak. China's earlier responses to ensure food security are discussed in a forthcoming article for China Agricultural Economic Review's special section on "Agriculture and Food Security under Novel Coronavirus Pneumonia (NCP) Emergency" (Chen, Fan, and Zhan 2020).

On February 5, Premier Li Keqiang called on ministries to coordinate to ensure an ample supply of food and effective logistics for delivering agricultural inputs, emphasizing the responsibility of local governors. To ensure the smooth logistical operation of regional agricultural and food supply chains, China has opened a "green channel" for fresh agricultural products and prohibited unauthorized roadblocks. The Ministry of Agriculture and Rural Affairs (MARA), Ministry of Transport, and Ministry of Public Security jointly issued a notice on January 30 urging relevant departments to coordinate to ensure effective logistics for agricultural products and materials. MARA issued a further emergency notice on February 4, calling on these departments to maintain market functions and ample supplies of meat, eggs, and milk.

To address the challenges facing the livestock sector, the National Development and Reform Commission and MARA jointly issued the "Notice on Promoting Multiple Measures and Promoting the Expansion of Production Guaranteed Supply of Poultry and Aquatic Products" to accelerate the resumption of production. The notice recommends gradual reopening of live poultry markets. The government also supports the construction of centralized slaughtering points, cold chain logistics, and other infrastructure to improve value chains. Feed production and slaughter enterprises are required to accelerate production in order to restore and increase the effective supply of livestock and poultry products. They are also being provided with production guidance and technical services to strengthen animal and plant epidemic prevention and control. The government also introduced financial supports for food production to prevent a decrease in the credit balances of agriculturerelated enterprises and reduce their financing costs. The Agricultural Bank of China has strengthened its services to support 349 key enterprises to ensure stable production and supply of agricultural products, with a loan balance of 41.4 billion yuan.

The burden on farming enterprises is mitigated by reducing or deferring their tax payments, reducing their rent, and deferring payment of their social insurance premiums. For example, the China Banking and Insurance Regulatory Commission issued the "Circular on Implementing Provisional Postponement in Principal and Interest Repayment for Loans to SMEs and Micro Enterprises (No.6)." Epidemic-hit small and medium-sized enterprises (SMEs) and micro firms, including small business owners and individual household businesses, can apply to their banks to defer repayment of principal and interest payable from January 25 to June 30, 2020; SMEs in China's Social Security Schemes are exempt from making employer contributions to pension, unemployment, and work-related injury insurance schemes between February and June 2020.

The use of e-commerce and delivery companies is another important means to ensure the food supply. As lockdown measures led to a huge spike in demand for home delivery of fresh groceries, e-commerce companies in China announced an in-app feature for contactless delivery, allowing a courier to leave an order in a convenient spot for customer pick-up, without person-to-person interaction. The use of these delivery platforms has helped resolve logistical challenges, while minimizing the potential risk of infection from visiting crowded food markets. 
Finally, ensuring food security requires a means to address the loss of workers' incomes caused by the interruption of economic activities, as these income effects may lead to drastic reductions in nutrition, especially for vulnerable groups. MARA and the Ministry of Human Resources and Social Security issued the "Circular on Implementation Plan" on March 26 for expanding local employment of returning rural migrant workers. The plan aims to promote local employment of migrant workers in agricultural production, as well as to help migrant workers return to work while ensuring their safe movement. A number of public welfare jobs were set up for migrant workers who face difficultly finding jobs on the market.

\section{Looking forward}

It's unclear how long the outbreak will last globally. As lockdowns and social distancing measures are implemented in the rest of the world, evidence and lessons from China not only have important policy implications for China to ensure a robust food system, but can also provide insight for other countries to help prevent food and nutrition security crises.

Continue to closely monitor food prices and strengthen market supervision, particularly in Wuhan and across Hubei and nearby provinces. Transparent market information will enhance the government's overall management of the food market and help to prevent the onset of panics, and can guide farmers in making rational production decisions. Potential for speculation remains at every stage of the supply chain, so there is also a need for sound market supervision. For processed products, supervision is also important to maintain food quality and safety.

Ensure smooth logistical operations of regional agricultural and food supply chains. China opened a "green channel" for fresh agricultural products and banned unauthorized roadblocks to ensure normal function of food supply chains. In addition, e-commerce and delivery companies can also play key logistical roles. For example, as lockdown measures have led to a huge spike in demand for home delivery of fresh groceries, e-commerce companies have announced an in-app feature for contactless delivery, allowing the courier to leave an order in a convenient spot for contactless customer pick-up. Making use of these delivery platforms could address many logistical challenges for obtaining food, while minimizing the potential risk of infection from visiting crowded markets to buy groceries.

Ensure the smooth flow of trade and make full use of the international market as a vital tool to secure food supply and demand. After reaching the phase-one trade deal with the United States to buy $\$ 40$ to $\$ 50$ billion of US farm products annually for the next two years, China has further announced it is cutting tariffs on US goods to ensure supplies and to alleviate economic and trade frictions. Meanwhile, increasing livestock product imports could help to buttress supply and stabilize the prices of domestic livestock products.

Protect vulnerable groups and provide employment services to migrant workers. International experience shows that the impacts of pandemics fall disproportionately on vulnerable populations, including children, pregnant women, elderly people, malnourished people, and people who are ill or immunocompromised. If many workers are unable to earn an income due to the disruptions of the outbreak, that risks an increase in poverty. As the government manages the epidemic response, it 
will be essential to restore the income streams of migrant workers and normal business operations. Workers are encouraged to find jobs near their homes, and migration should be managed to prioritize their health. Policies to match workers with companies are being implemented. But to work, these policies will require close supervision.

Regulate wild food markets to curb the source of the disease. Many zoonotic diseases originate from wildlife; HIV, Ebola, MERS, and SARS have all made the leap from wildlife to humans, spawning international outbreaks. On January 26, the government announced a temporary ban on wildlife trade from markets, restaurants, and e-commerce until the epidemic is over. To avoid future epidemics, on February 24, the government further issued the decision to ban the trade and consumption of wildlife as food. Use of wild animals for medicine, pets, and scientific research will be subject to strict examination and approval by relevant departments.

Originally published February 12, 2020, and updated June 10, 2020.

For more on China's early responses to COVID-19, see Z. Chen, S. Fan, and Y. Zhan, "COVID-19 and Food Security: Early Responses, Impact, and Lessons from China," China Agricultural Economic Review, 2020 (forthcoming). 